\title{
Hyphal-sheath polysaccharides in fungal deterioration
}

\author{
A. Gutiérrez ${ }^{* a, b}$, M.J. Martínez $z^{a}$, G. Almendrosc, F.J. González-Vilab, A.T. \\ Martínez $^{\mathrm{a}}$

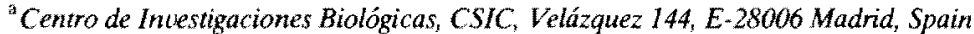 \\ 'Instituto de Recursos Naturales y Agrobiologia, CSIC, Apartado 1052, E-41080 Seville, Spain \\ 'Centro de Ciencias Medioambientales, CSIC, Serrano 115 dpdo, E-28006 Madrid, Spain
}

\begin{abstract}
The extracellular polysaccharides produced by some fungi involved in the deterioration of wood (Pleurotus species) and stone (Ulocladium atrum) were isolated and characterized. Both are $\beta-(1 \rightarrow 3)$-linked glucans with considerable branching degree, as revealed by methylation analysis and ${ }^{13} \mathrm{C}-\mathrm{NMR}$. The Pleurotus glucans present the most complex structure and the study was followed by the analysis of the low-molecular weight products and the partially degraded polysaccharides obtained after periodate oxidation or acetolysis. The Pleurotus species produced ligninolytic enzymes which play a role in wood deterioration. On the other hand, Ulocladium atrum produces black pigments (melanins) involved in stone biodarkening, which were studied by analytical pyrolysis and chemical degradation. The occurrence of similar extracellular polysaccharides in fungi from very different taxonomic groups, i.e. ascomycetous dematiaceous and white-rot basidiomycetes, suggests that such polysaccharides are playing some basic functions in hyphal growth on different substrates. In addition, they probably play specific roles in biodeterioration of stone, including the formation of extracellular melanin-polysaccharide stable complexes; and wood, providing a microenvironment for the action of ligninolytic enzymes and redox intermediates.
\end{abstract}

Keywords: Pleurotus; Ulocladium; Biodeterioration; Sheath; White-rot; Ligninolytic enzymes; Melanins; Biodarkening; Wood; Stone; Extracellular polysaccharides; Methylation analysis; ${ }^{13} \mathrm{C}-\mathrm{NMR}$; Analytical pyrolysis

\section{Introduction}

A variety of fungi are involved in the biodeterioration of building materials, including wood and stone. Stone biodeterioration has received considerable attention during the last few years, after recognizing the biological origin of the alteration

${ }^{*}$ Corresponding author. processes suffered by many stone monuments and historical buildings. On the other hand, wood deterioration by fungi is widespread due to the comparatively low resistance of wood to biological agents.

Fungal alteration of lithic materials is produced by species from different taxonomic groups (mainly ascomycetes and ascomycetous deuteromycetes) through rather unspecific mechanisms [1]. These include mechanical action by 
hyphae, release of organic acids acting in the dissolution or the chelation of stone cations, and synthesis of dark pigments (fungal melanins) responsible for stone darkening through the formation of black patinae on monuments. The fungal melanins, produced by different biosynthetic pathways [2], present high resistance to biodegradation, and their composition and structure have been analyzed regarding the formation of soil humus colloids [3-10].

Wood deterioration by fungi is of great economic importance due to the use of wood as a building material, and a variety of treatments have been developed for its protection against fungal attack [11]. Moreover, wood biodeterioration also affects the artistic and cultural property $[12,13]$, since wood constitutes an important structural and decorative element in most historical buildings and monuments. Wood presents a variable resistance to biodegradation, which is influenced by the total content and monomer composition of lignin. The structural plant polysaccharides (i.e. cellulose and hemicellulose) are protected by the recalcitrant lignin polymer [14]. Only a group of basidiomycetes responsible for the white-rot of wood, can degrade the lignin macromolecule. A reduced number of them have largely been investigated as important wood deterioration agents, e.g. Serpula lacrymans [15], but a list of 100 fungi involved in the decay of construction wood, including Pleurotus species, has been reported [16]. In spite of recent important progress in the study of the mechanisms of lignin attack [17-20] by white-rot fungi, the role of the different ligninolytic enzymes and intermediate compounds produced during fungal degradation is far from being definitively unravelled.

A large number of organisms colonizing terrestrial habitats (fungi, algae, bacteria, etc.) produce polysaccharide-containing extracellular structures, the so-called glycocalyx, involved in adhesion, recognition, pathogenicity, etc. [21]. In many fungi, these polysaccharides form a sheath coating mycelial hyphae. Different fungal polysaccharides, extracted from fruiting bodies or produced in liquid culture media, have been characterized [22-25]. The extracellular polysaccharides are the major constituents of the hyphal sheath formed when the fungus grows on natural substrates.

In the present study, the composition and structure of extracellular polysaccharides produced by species of the genus Pleurotus and by Ulocladium atrum are investigated. These organisms were selected as representative of basidiomycetes producing white-rot decay of wood, and of ascomycetous black-fungi, causing stone biodarkening, respectively. In order to understand the mechanisms of wood and stone deterioration by these fungi, the ligninolytic enzymes produced by Pleurotus species and the dark pigments synthesized by $U$. atrum were analyzed. Finally, the role of the polysaccharide sheath as a microenvironment where the biodeterioration processes take place, is discussed.

\section{Materials and methods}

\subsection{Fungi and growth conditions}

Five Pleurotus strains were studied: P. cornucopiae CBS 383.80, P. floridanus MUCL 28518, $P$. pulmonarius CBS 507.85, P. ostreatus CBS 411.71, and P. sajor-caju MUCL 29757. The following medium was used for culture inoculum: 10 g glucose, $2 \mathrm{~g}$ ammonium tartrate, $1 \mathrm{~g} \mathrm{KH} \mathrm{KO}_{4}, 1$ g yeast extract, $0.5 \mathrm{~g} \mathrm{MgSO}_{4} \cdot 7 \mathrm{H}_{2} \mathrm{O}, 0.5 \mathrm{~g} \mathrm{KCl}, 1$ litre water, and $1 \mathrm{ml}$ of a mineral solution $(10 \mathrm{mg}$ $\mathrm{B}_{4} \mathrm{O}_{7} \mathrm{Na}_{2} \cdot 10 \mathrm{H}_{2} \mathrm{O}, 7 \mathrm{mg} \mathrm{ZnSO}_{4} \cdot 7 \mathrm{H}_{2} \mathrm{O}, 5 \mathrm{mg}$ $\mathrm{FeSO}_{4} \cdot 7 \quad \mathrm{H}_{2} \mathrm{O}, 1 \mathrm{mg} \mathrm{CuSO}_{4} \cdot 5 \quad \mathrm{H}_{2} \mathrm{O}, 1 \mathrm{mg}$

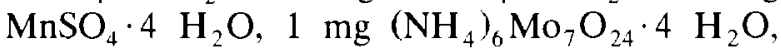
and $100 \mathrm{ml}$ water). After 15 days of stationary growth at $28^{\circ} \mathrm{C}$, the mycelium was homogenized and used as inoculum. Production of enzymes and polysaccharide was assessed in a modification of the above medium containing $30 \mathrm{~g}$ glucose and $0.6 \mathrm{~g}$ ammonium tartrate per litre, distributed in 1-litre flasks (containing $400 \mathrm{ml}$ of medium) incubated at $28^{\circ} \mathrm{C}$ and $200 \mathrm{rev} . / \mathrm{min}$.

Ulocladium atrum IJFM 7339 was grown at $30^{\circ} \mathrm{C}$ in a culture medium containing: $30 \mathrm{~g}$ malt extract, $2 \mathrm{~g} \mathrm{NaNO}_{3}, 1 \mathrm{~g} \mathrm{~K}_{2} \mathrm{HPO}_{4}, 0.5 \mathrm{~g} \mathrm{KCl}, 0.5 \mathrm{~g}$ $\mathrm{MgSO}_{4} \cdot 7 \mathrm{H}_{2} \mathrm{O}, 10 \mathrm{mg} \mathrm{FeSO} \mathrm{H}_{4} \cdot 7 \mathrm{H}_{2} \mathrm{O}$, in 1 litre of water $(\mathrm{pH} 5)$. Spore suspensions from $2 \%$ malt extract agar were used for inoculating $400 \mathrm{ml}$ of liquid medium in 1-l flasks. The effect of different 
growth conditions (stationary and shaken at 200 rev./min) and carbon sources (glucose and wheat straw) on polysaccharide and melanin production were also investigated.

\section{L. rotysacchanae charactenzation}

Different incubation times were used for polysaccharide production, 20 days for Pleurotus spp and 2 days for $U$. atrum, to obtain peak production. They were precipitated from the culture filtrate with ethanol ( $50 \%$ vol. $/$ vol.) and dialyzed in deionized water. Some samples were freeze-dried and others were kept in ethanol to prevent further solubility problems observed with the dried samples of Pleurotus polysaccharide. Acid hydrolysis was carried out with $2 \mathrm{M} \mathrm{H}_{2} \mathrm{SO}_{4}$ at $100^{\circ} \mathrm{C}$ for $16 \mathrm{~h}$. Methylation analysis was performed by the method of Hakomori [26] modified by Jansson et al. [27], using polysaccharide dialyzed against anhydrous dimethylsulfoxide. Periodate oxidation was carried out as described by Aspinall and Ferrier [28], and followed by complete $\left(0.5 \mathrm{M} \mathrm{H}_{2} \mathrm{SO}_{4}\right.$ at $100^{\circ} \mathrm{C}$ for $\left.16 \mathrm{~h}\right)$ and mild hydrolyses $\left(1 \mathrm{M} \mathrm{H}_{2} \mathrm{SO}_{4}\right.$ at $50^{\circ} \mathrm{C}$ for $24 \mathrm{~h}$ ). The sugars released by the complete hydrolysis were analyzed by $\mathrm{GC}$ as alditol acetates. Acetolysis was performed by the method described by Fabre et al. [29], and the sugars released were analyzed by TLC and GC. Partially degraded polysaccharides from periodate oxidation followed by mild hydrolysis, or acetolysis were subjected to methylation analysis. FT-IR spectra were obtained using $1 \mathrm{mg}$ of freeze-dried polysaccharide. The solution ${ }^{13} \mathrm{C}$ NMR was performed using a polysaccharide preparation dissolved in $0.1 \mathrm{M} \mathrm{NaOD}$ or in $\mathrm{D}_{6}$-dimethylsulfoxide. In the case of Pleurotus polysaccharide (which turns insoluble after drying), a preparation was obtained by dissolving in the latter solvent a sample of polysaccharide recently precipitated in ethanol, and removing the traces of ethanol after obtaining the suitable concentration. Solid-state ${ }^{13} \mathrm{C}$-NMR using cross-polarization and magic-angle spinning (CPMAS) was carried out on samples of freeze-dried polysaccharide.

\subsection{Enzyme analyses}

Laccase (EC 1.10.3.2) activity was measured using $5 \mathrm{mM}$ ABTS (2,2'-azino-bis(3-ethylbenzothiazoline-6-sulfonic acid)) in $100 \mathrm{mM}$ acetate buffer, pH $5.5\left(\epsilon_{436}=29300 \mathrm{M}^{-1} \mathrm{~cm}^{-1}\right)$. Arylalcohol oxidase (AAO) (EC 1.1.3.7) activity was determined from the absorbance increase due to

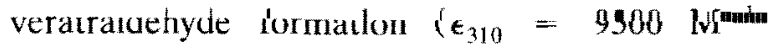
$\mathrm{cm}^{-1}$ ) from $5 \mathrm{mM}$ veratryl alcohol in $100 \mathrm{mM}$ phosphate buffer, $\mathrm{pH}$ 6.0. Two different procedures were used to prove the presence of lignin peroxidase (LiP) (EC 1.11.1.14) activity: (i) as the $\mathrm{H}_{2} \mathrm{O}_{2}$-dependent oxidation of veratryl alcohol to veratraldehyde, using $2 \mathrm{mM}$ veratryl alcohol in $100 \mathrm{mM}$ Na-tartrate, $\mathrm{pH} 3.0$, and $0.4 \mathrm{mM} \mathrm{H}_{2} \mathrm{O}_{2}$; and (ii) by the oxidation of Azure $\mathrm{B}$ monitored by absorbance decrease at $651 \mathrm{~nm}$, using $0.032 \mathrm{mM}$ Azure $\mathrm{B}$ in $100 \mathrm{mM} \mathrm{Na-tartrate,} \mathrm{pH} 4.5$, and 0.4 $\mathrm{mM} \mathrm{H} \mathrm{O}_{2} \mathrm{O}_{2}$ [30]. Mn-dependent peroxidase (MnP) (EC 1.11.1.13) was measured using phenol-red $(0.01 \%$ wt. $/$ vol. $)$ in the presence of $0.1 \mathrm{mM} \mathrm{H}_{2} \mathrm{O}_{2}$ and $0.1 \mathrm{mM} \mathrm{MnSO}_{4}$ in $100 \mathrm{mM} \mathrm{Na}$-tartrate $(\mathrm{pH}$ 5.0). The reaction mixture was incubated at room temperature for $30 \mathrm{~min}$ and stopped by addition of $\mathrm{NaOH}\left(0.2 \mathrm{M}\right.$ final concentration) $\left(\epsilon_{610}=\right.$ $\left.4460 \mathrm{M}^{-1} \mathrm{~cm}^{-1}\right)$. Appropriate controls were used, including reactions without $\mathrm{H}_{2} \mathrm{O}_{2}$ in LiP and $\mathrm{MnP}$ tests. The results were given as international units of enzyme activity ( $\mu \mathrm{mol} \mathrm{min}^{-1}$ ).

\subsection{Melanin studies}

Two-week cultures of $U$. atrum were centrifuged, and the fungal biomass was washed and dried at $60^{\circ} \mathrm{C}$. Pyrolysis was performed at $500^{\circ} \mathrm{C}$ in a Curie-point pyrolyzer (Fischer 0316) coupled to a Fisons gas chromatograph-mass spectrometer (fitted with a capillary SPB-5 column, and programmed from 25 to $280^{\circ} \mathrm{C}$ at $5^{\circ} \mathrm{C} \mathrm{min}{ }^{-1}$ ). For melanin isolation, $1 \mathrm{~g}$ of $U$. atrum biomass was suspended in $25 \mathrm{ml}$ of $0.4 \mathrm{M} \mathrm{NaOH}$ and subjected to ultrasonic disruption. The volume was then adjusted to $100 \mathrm{ml}$ with distilled water, and the bottle was shaken for $12 \mathrm{~h}$. Turbidity was removed by centrifugation $(48200 \times g)$, and the melanin was precipitated from the supernatant solution with $\mathrm{HCl}$ at $\mathrm{pH} \mathrm{2,} \mathrm{then} \mathrm{purified} \mathrm{by} \mathrm{cen-}$ trifugation at alkaline $\mathrm{pH}$, reprecipitation and dialysis. Sephadex G-25 gel chromatography of melanin was performed using $50 \mathrm{mM} \mathrm{NaOH}$ as 
eluent. For structural studies, the freeze-dried melanin was degraded by acidic $\mathrm{K}_{2} \mathrm{~S}_{2} \mathrm{O}_{8}$ or by alkaline $\mathrm{KMnO}_{4}$. The $\mathrm{K}_{2} \mathrm{~S}_{2} \mathrm{O}_{8}$ degradation was carried out according to Martín et al. [31], and the $\mathrm{KMnO}_{4}$ oxidation was performed as described by Matsuda and Schnitzer [32], including diazomethane methylation. The ethyl acetate extract, containing degradation products, was dehydrated, evaporated, resuspended in methanol, methylated with ethereal diazomethane, and analyzed by GC-MS, using a capillary OV-101 column operating from $100^{\circ} \mathrm{C}$ to $270^{\circ} \mathrm{C}$ at $6^{\circ} \mathrm{C} \mathrm{min}{ }^{-1}$.

\section{Results and discussion}

\subsection{Structural analyses of the extracellular polysaccharides}

The fungi studied produced extracellular polysaccharides in liquid cultures, which can also be observed when growing on natural substrates (Fig. 1). The crude polysaccharide precipitated from $U$. atrum cultures was a dark melanin-protein-polysaccharide complex $(50 \%$ carbohydrate content and 15-20\% melanin and protein contents), whereas those from Pleurotus species did not bear associated pigments and included low protein content. Several attempts to purify $U$. atrum polysaccharide were unsuccessful. However, on thawing the frozen crude polysaccharide a colorless supernatant was obtained, and the melanin was removed by centrifugation.

The analysis of the products of acid hydrolysis revealed that the polysaccharides under study consist mainly of glucose units. These are linked by $\beta$-type bonds, as evidenced by the $890 \mathrm{~cm}^{-1}$ band in the IR spectra. The identification of the sugar carbons involved in intermonomer linkages requires additional analyses, mainly based on methylation-acid hydrolysis or ${ }^{13} \mathrm{C}-\mathrm{NMR}$. Such approaches revealed predominance of $(1 \rightarrow 6)$ branched $\beta-(1 \rightarrow 3)$-glucans. The number of terminal units or branching points was similar to that of trimethylated units indicating that $30-50 \%$ of units in the main backbone present a branching point.

The ${ }^{13}$ C-NMR spectra (Fig. 2) of Pleurotus and Ulocladium polysaccharides provided the confirmation of the existence of substituted $\mathrm{C}_{1}$ (103 and $104 \mathrm{ppm}), \mathrm{C}_{3}(86$ and $87 \mathrm{ppm})$ and $\mathrm{C}_{6}(70 \mathrm{ppm})$, corresponding to the main backbone linkages and branching points in the polymer. In addition to the signals corresponding to free $\mathrm{C}_{4}(69 \mathrm{ppm}), \mathrm{C}_{5}$

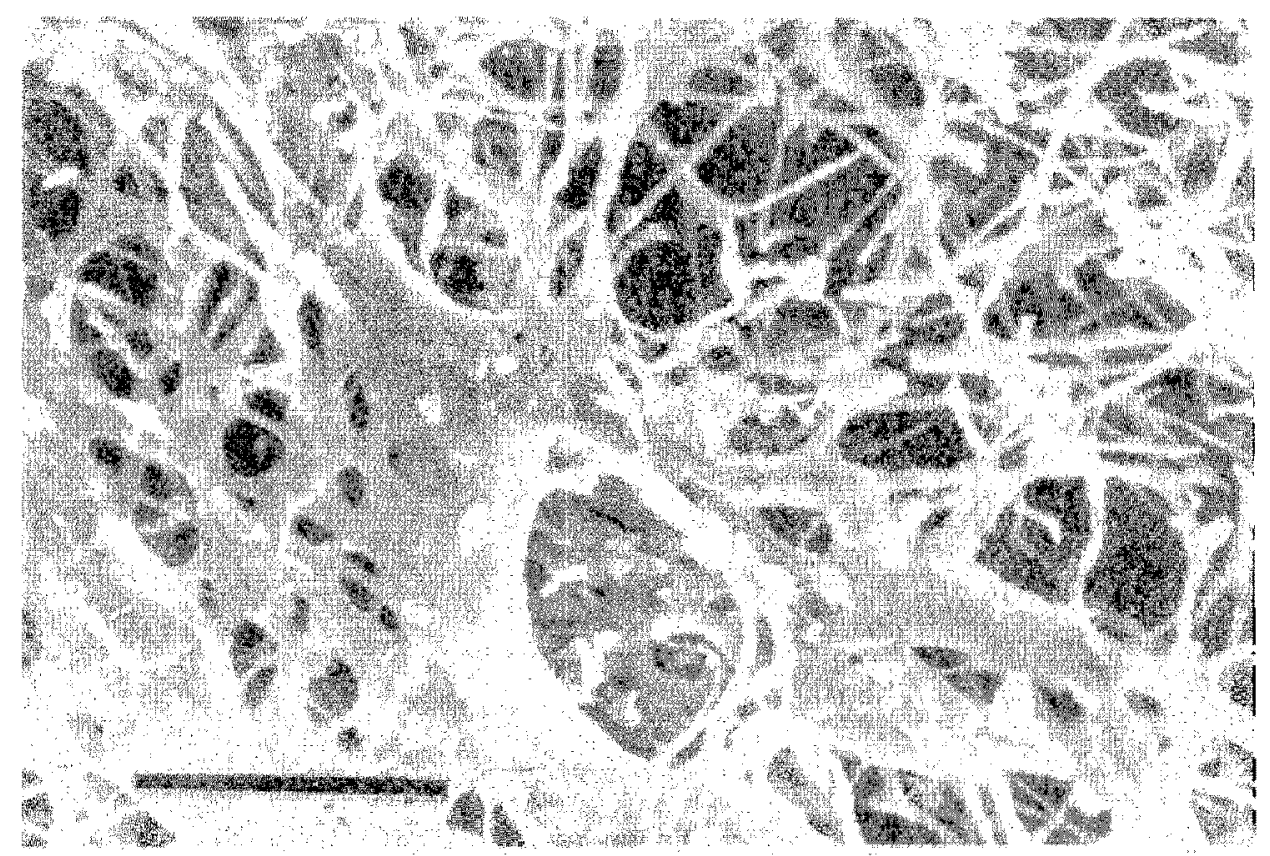

Fig. 1. Scanning electron microscopy of fungal mycelium, showing extracellular polysaccharide on hyphae (the bar indicates 50 $\mu \mathrm{m})$. 
(76 and $77 \mathrm{ppm}$ ) and $\mathrm{C}_{6}(61 \mathrm{ppm}$ ), a small signal for free $\mathrm{C}_{3}(75 \mathrm{ppm})$ was also observed, corresponding to terminal units. The ${ }^{13} \mathrm{C}$-NMR spectrum of $U$. atrum polysaccharide (Fig. $2 \mathrm{~A}$ ) was similar to that obtained from laminarin, a $\beta-(1 \rightarrow$ 3)-glucan, although the signal corresponding to substituted $C_{6}$ was more intense. Signals at 74 and $73 \mathrm{ppm}$ in Pleurotus polysaccharide were tentatively assigned to two different $\mathrm{C}_{2}$ types. Additional studies using specific pulse sequences are actually in progress to confirm the nature of some of the signals obtained. The CPMAS ${ }^{1.3} \mathrm{C}$ NMR spectra of freeze-dried polysaccharide have poor resolution and were unsuitable for definitive structural conclusions, however the major peaks are coincident with those obtained in solution.
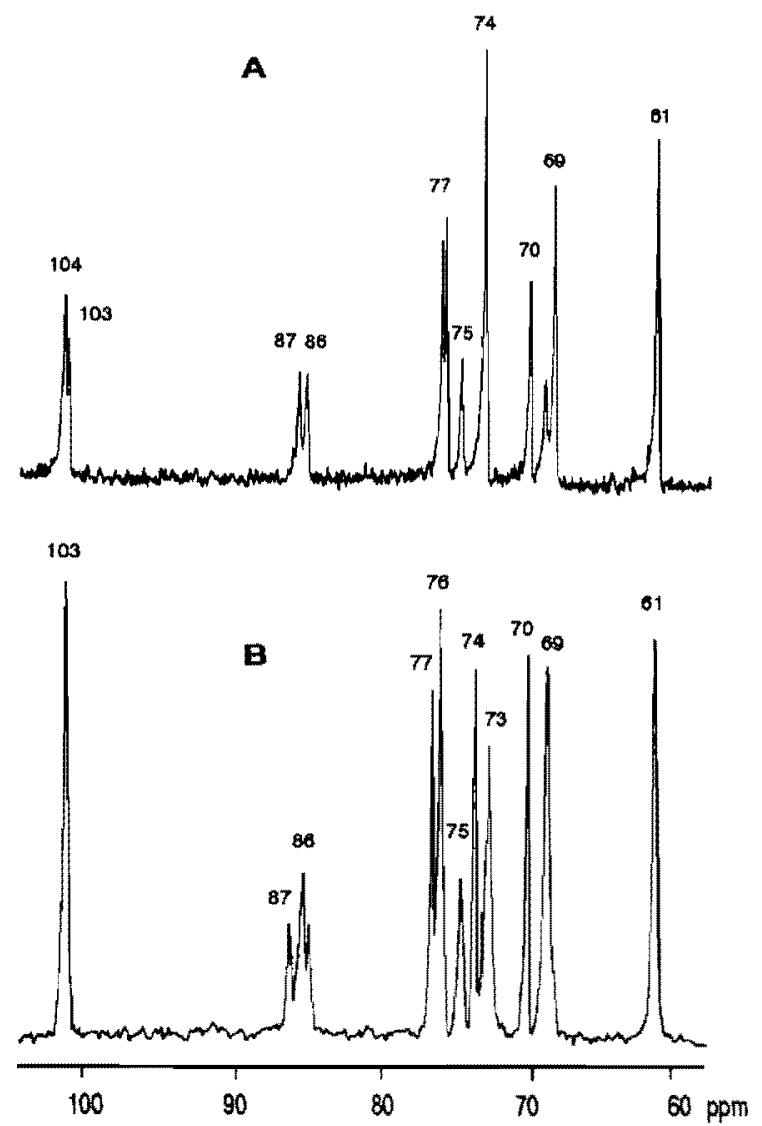

Fig. $2 .{ }^{13} \mathrm{C}$-NMR spectra of the extracellular polysaccharides from Ulocladium atrum (A) and Pleurotus pulmonarius (B).
In the Pleurotus polysaccharide, intermediate (trimethylated) chain units were also mainly $(1 \rightarrow$ 3)-linked, but small amounts of $(1 \rightarrow 4)$-linked units were noted after methylation analysis. The sugars obtained from branching points were mainly 2,4-dimethylated, indicating 1,3,6-substituted units in the original polysaccharide, but some amount of 3,4-dimethylated sugars was also found in Pleurotus polysaccharides. Slight differences between extracellular polysaccharides from the different species of Pleurotus studied were observed after methylation analysis. However, such differences were only quantitative (i.e. affecting the relative abundance of some linkages) and similar to those expected between polysaccharides from the same fungus when grown under different conditions or for different incubation times.

Two partial degradation procedures were also used to complement the structural analysis of the polysaccharides produced by Pleurotus species. The periodate oxidation breaks $\mathrm{C}-\mathrm{C}$ bonds between contiguous carbons bearing hydroxyl groups. Consequently, the backbone of $\beta-(1 \rightarrow 3)$ glucans is not affected, but sugars linked by minor $\beta$-( $1 \rightarrow 4)$ bonds and terminal units are effectively degraded. The methylation analysis of the polysaccharide recovered after a single treatment with periodate and mild hydrolysis, revealed the features of a linear $(1 \rightarrow 3)$-linked glucan. This confirmed the identification of terminal, and $(1 \rightarrow$ 4)-linked units, which were removed by oxidation. Moreover, it suggested the existence of poiysaccharide branches consisting of a single sugar unit, which was removed by periodate oxidation (although the presence of small amounts of $(1 \rightarrow 4)$ linked units prevents a general conclusion from these results). In order to obtain additional information on the above structure, a second method for partial degradation was used. Acetolysis constitutes a chemical procedure for the selective degradation of $(1 \rightarrow 6)$-linkages in polysaccharides. In the case of $\beta-(1 \rightarrow 6)$-branched glucans, the resulting polysaccharide should present a linear structure, and the analysis of the mono- or oligosaccharides released should inform on the sugar composition of polysaccharide side-chains. 
In fact, a linear glucan containing mainly $(1 \rightarrow 3)$ linkages was recovered by acetolysis of the extracellular polysaccharide from Pleurotus, confirming the existence of $(1 \rightarrow 6)$-branched units. Moreover, glucose was identified after acetolysis, corresponding to polysaccharide branches consisting of a single sugar unit.

\subsection{Ligninolytic enzymes produced by Pleurotus species}

The different Pleurotus species studied presented a similar pattern of enzymatic activities involved in degradation of wood lignin. After 15 days growth in the $\mathrm{N}$-limited medium, the following values for AAO activity were found: ca. $110 \mathrm{U}^{-1}$ in $P$. pulmonanus and $P$. comucopiae, $40 \mathrm{U}^{-1}$ in $P$. ostreatus and ca. $10 \mathrm{U}^{-1}$ in $P$. sajor-caju and $P$. floridanus. The levels of laccase were considerably lower: ca. $15 \mathrm{U}^{-1}$ in $P$. sajorcaju and $P$. floridanus, $8 \mathrm{U} \mathrm{I}^{-1}$ in P. pulmonarius and ca. $5 \mathrm{Ul}^{-1}$ in P. comucopiae and P. ostreatus. No LiP was detected in any of the cultures, and the levels of $\mathrm{MnP}$ were low. However, the production of the latter enzyme increased considerably when peptone was used as the nitrogen source [33].

The activities of the above enzymes also presented a characteristic evolution during fungal growth. Laccase appeared first, showing a main peak during the growth phase. $\mathrm{MnP}$ and $\mathrm{AAO}$ appear when the $\mathrm{N}$ source was nearly exhausted. The former enzyme showed a main activity peak, followed by a rapid decline, whereas AAO maintained a relatively high activity during most of the secondary growth, after attaining the maximum levels in the first days of this period.

\subsection{Black pigments (melanins) produced by \\ Ulocladium atrum}

The Py-GC-MS analysis of the biomass from $U$. atnum reflected the presence of carbohydrates and considerable amounts of fatty acids (Fig. 3), from which the $\mathrm{C}_{16}$ and $\mathrm{C}_{18: 1}$ members were the most abundant (peaks 31 and 32). It has been reported that black patinae coating marble monu- ments also yields considerable amounts of fatty acids upon pyrolysis [34].

The characteristic pyrolysis products of carbohydrates, including sheath polysaccharides, were identified in the first half of the chromatogram (peaks 3, 5, 7, 11-13,18, 20, 21, 24 and 26). In addition to the pyrolysis products listed in Fig. 3, two dialkyl phthalates derived from plastic contamination, and three unidentified compounds from carbohydrate pyrolysis (indicated with asterisks in Fig. 3) were also detected. Different aromatic compounds could be derived from melanins, although some of them have also been identified after pyrolysis of non-pigmented fungi [35]. The alkylbenzenes could be derived from the pyrolysis of the perylenequinonic pigments discussed below. The presence of some compounds identified as cyclohexane and cyclohexene derivatives is noteworthy. The latter have been found after pyrolysis of the melanin from Stachybotrys atra [36], yielding the most abundant pyrolysis products.

An acid-insoluble black fraction was isolated from the alkaline extract from $U$. atrum biomass. A characteristic of this melanin is the presence of a significant proportion of condensed green pigments, which were separated by Sephadex G-25 chromatography and identified by their typical maxima of dihydroxyperylenequinonic compounds [37]. Normal and branched fatty acids were obtained after both degradation procedures, palmitic acid being the most abundant. Persulfate oxidation released the most diagnostic compounds, including a series of phenolic and benzenecarboxylic acids in addition to fluorene, naphthalene and biphenyl. Moreover, significant proportions of aliphatic products (mainly dibasic and monobasic acids and alkanes) were detected. The presence of some of the above compounds could be explained with regard to the biosynthetic pathways of fungal pigments derived from binaphthyl or perylene [38], whereas a high proportion of fatty acids is typical of fungal melanin preparations, as reported by Martín et al. [6]. Benzenecarboxylic acids represented a small proportion of the permanganate digest, and phenolic acids were missing, excepting a chloro-derivative (dichloro-anisic acid). To all appearances, $\mathrm{KMnO}_{4}$ 


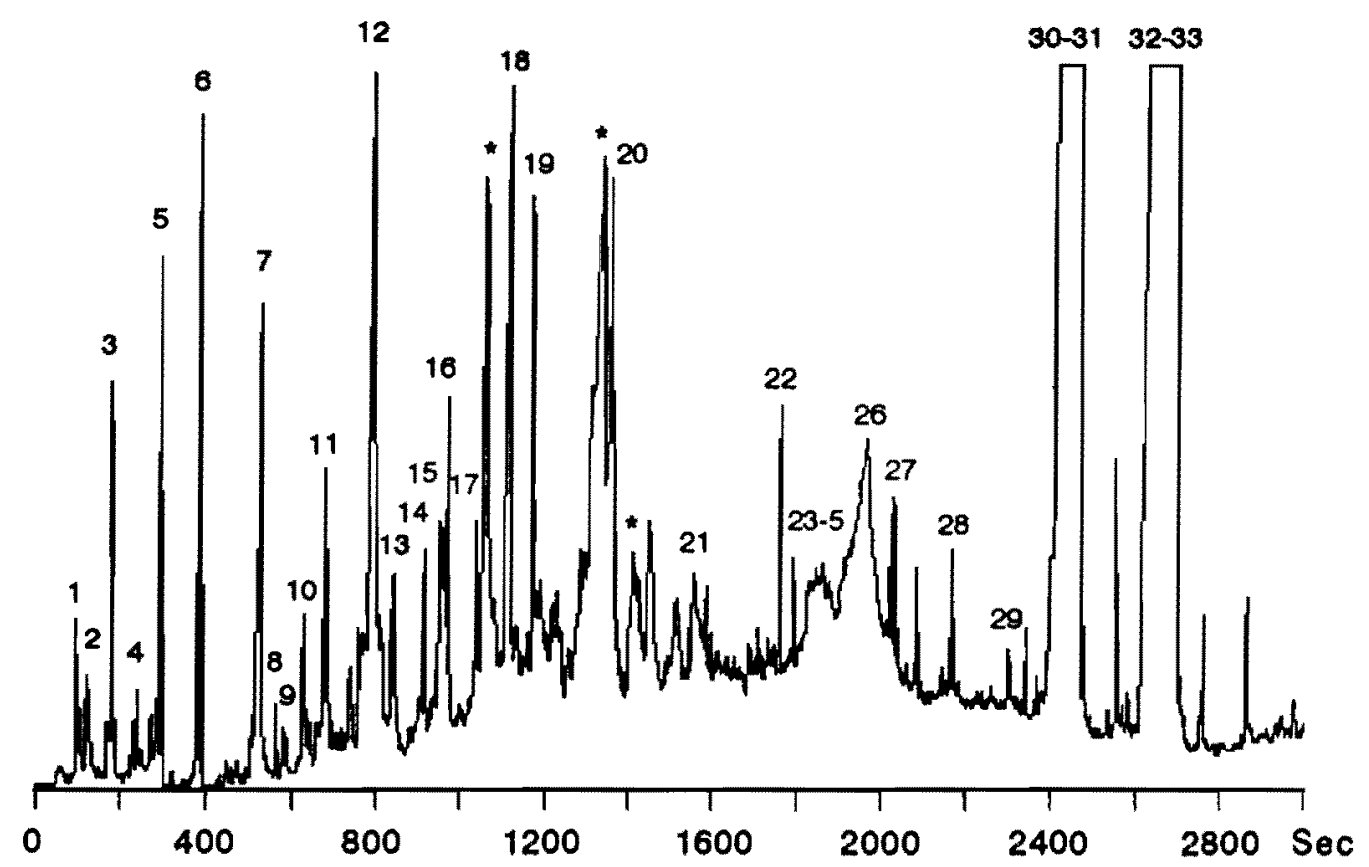

Fig. 3. Py-GC-MS of Ulocladium atrum biomass. Peak identification: $1, \mathrm{SO}_{2} ; 2$, acetone + furan; 3 , methylfuran; 4 , benzene; 5 , dimethylfuran; 6 , acetic acid + toluene; 7 , furaldehyde; $8, \mathrm{C}_{2}$-alkylbenzene; $9, \mathrm{C}_{2}$-alkylbenzene; 10 , styrene $+\mathrm{C}_{2}$-alkylbenzene; 11 , trimethylfuran; 12 , methylfuraldehyde $+\mathrm{C}_{3}$-alkylbenzene; 13 , methylpyranone; 14 , alkylcyclohexene; $15, C_{3}$-alkylbenzene; 16 , $\mathrm{C}_{4}$-alkylbenzene; 17 , phenol; 18 , levoghucosenone; $19, \mathrm{C}_{5}$-alkylbenzene; 20 , dianhydro- $\alpha$-D-glucopyranose $+\mathrm{C}_{6}$-alkylbenzene; 21 , dideoxyglycerohexenpyranosulose; 22 , pentadecane; 23 , alkylbiscyclohexane; 24 , levomannosane; $25, C_{4}$-alkylbenzene; 26 , levoglucosane; 27, dodecanoic acid; 28 , tetradecanoic acid; 29 , pentadecanoic acid; 30 , hexadecenoic acid; 31 , hexadecanoic acid; 32 , octadecenoic acid; and 33, octadecanoic acid (three unidentified compounds from carbohydrate pyrolysis are indicated with asterisks).

oxidation seems a too drastic method for fungal melanins, and other aromatic compounds detected after persulfate oxidation were probably destroyed.

\subsection{Sheath polysaccharides in stone and wood biodeterioration}

An important group of extracellular polysaccharides produced by ascomycetous and basidiomycetous fungi, including Pleurotus species and $U$. atrum, are formed by a backbone of $\beta-(1 \rightarrow 3)$ linked glucose units, exhibiting more or less short branches formed from $\beta-(1 \rightarrow 6)$ linkages (Table $1)$. These $(1 \rightarrow 6)$-branched, $(1 \rightarrow 3)$-linked $\beta$-Dglucans can present structural variations, due to differences in: (i) polymerization degree; (ii) frequency of branching; (iii) length of branches; and (iv) presence of minor linkages. However, the existence of similar extracellular polysaccharides in fungi from very different taxonomic groups, suggests that they could present an old common evolutive origin and play some basic functions in fungal physiology.

Three general roles of the extracellular polysaccharides forming mucilages or sheaths in fungi or bacteria, are related to: (a) adhesion to the substrate; (b) protection against dehydration; and (c) storage of a carbon source. It has been shown by transmission electron microscopy that the extracellular sheath covers most of the internal surface of the wood fibers colonized by fungi and fixes the hyphae to the cell-wall to be degraded [39-41]. On the other hand, sheath polysaccharides play an important role in the formation of biofilms, which include mixed populations of prokaryotic and eukaryotic organisms responsible for stone deterioration. Protection against dehydration can be considered as a gen- 


\begin{tabular}{lc}
\hline Ascomycetous fungi & \\
Monilinia fructigena (= Sclerotinia frictigena) & 50 \\
Ulocladium atrum & 50 \\
Aureobasidium pullulans (= Pullularia pullulans) & $33^{\circ}$ \\
Botryts cinerea & 33 \\
Claviceps spp. & $25-33$ \\
Pyricularia oryzae & 17 \\
Basidiomycetous fungi & \\
Hirneola auricula-judae (= Auncularia auricula-judae) & 66 \\
Phanerochaete chnsosporium & 50 \\
Pleurotus spp. & 33 \\
Lentinula edodes (= Lentinus edodes) & 40 \\
Schizophyllum commune & 33 \\
Athelia rolfsii (anamorph: Sclerotium rolfsii) & 33 \\
Wolfiporia cocos (= Poria cocos) & Very low \\
\hline it From references [21.22,25]. & \\
"Backbone units supporting a branch (\%). &
\end{tabular}

eral function of extracellular polysaccharides. In fact, the volume of the hyphal sheath can be several times higher than the cytoplasmic volume, and an important amount of water will be retained by the hydrophilic polysaccharide under the semi-dryness conditions characterizing the natural environment of fungi involved in biodeterioration processes. In this way, the gelified polysaccharide surrounding hyphae constitutes a barrier protecting the fungus not only from dryness but also from other environmental injuries. Moreover, the extracellular glucans could also be considered as storage compounds, which are consumed by the fungus when exogenous carbon sources are exhausted.

In addition to the general features discussed above, other roles of the extracellular polysaccharides concern some common aspects of the biodeterioration of different materials: (d) facilitating diffusion and concentration of decaying enzymes; and (e) providing a medium with suitable ionic and $\mathrm{pH}$ conditions. An important function of the extracellular polysaccharides is to facilitate the enzymatic attack to the substrate to be degraded. Firstly, the immobilization of different fungal enzymes on polysaccharide filaments has been shown by transmission electron microscopy using anti- bodies and polysaccharide staining [42-44]. In fact, the glucans exhibit a rather unspecific capacity for binding proteins. Secondly, the polysaccharide could provide an adequate medium for the action of these enzymes through the modification of $\mathrm{pH}$ and the concentration of certain ions as a consequence of its high specific area and chelating action.

Finally, the extracellular polysaccharides participate in processes which are specific to the fungal deterioration of different substrates. In the case of stone (Fig. 4), the formation of black patinae is carried out through successive biotic and abiotic processes which require the transformation of stone surface into a hydrophilic microenvironment suitable for microbial colonization. In a second phase, biopolymers secreted by fungi or released during autolysis, undergo uncontrolled copolymerization. Enzyme-catalyzed oxidative reactions play an additional role in the condensation of low molecular weight compounds. The advanced stages of the biodarkening process include abiotic reactions contributing to the hardening of the polymer material and its physicochemical fixation to the stone surface. Water-repellent polyalkyl structures can be formed from auto-oxidation of the unsaturated fungal lipids 

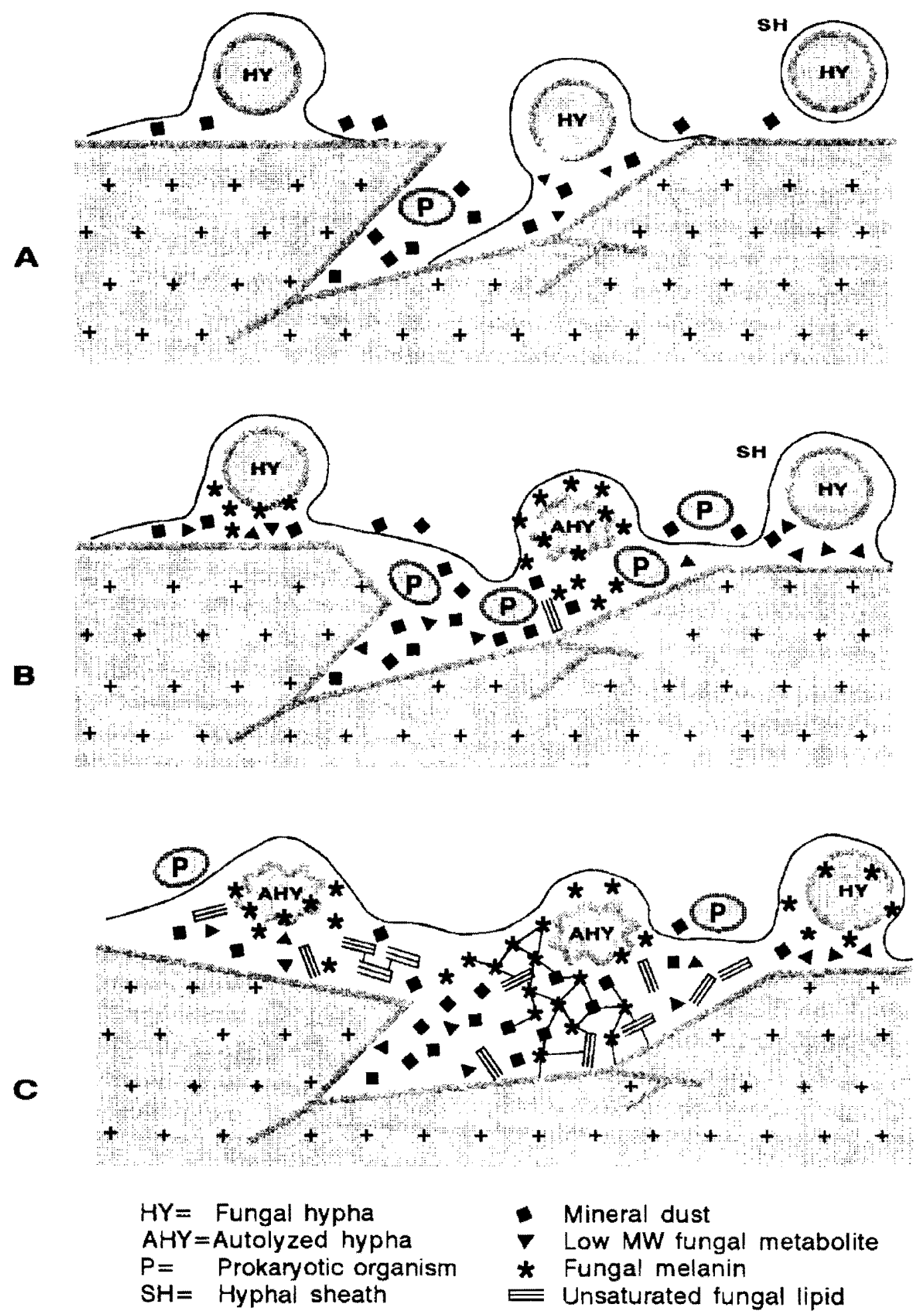

Fig. 4. Three phases of stone deterioration by dematiaceous fungi. Polysaccharide slicath, autolyzed hyphae, low molecular-weight and macromolecular fungal metabolites involved in formation of black patina, are indieated. 
through clay-catalyzed, UV-radiation favored reactions. Such processes are similar to those characteristics for the formation of humus material in lignin-lacking sediments, and have also been considered to contribute to the formation of the polyalkyl moiety of the insoluble fractions of humus [45].

Sheath polysaccharides are directly involved in the following aspects of stone biodeterioration: (f) adhesion of aerosols; ( $\mathrm{g}$ ) solubilization of stone minerals; ( $h$ ) deposition of carbonates and bicarbonates; (i) formation of complexes with melanin, and other organic and mineral compounds. The sheath polysaccharide, in addition to those produced by prokaryotic organisms, facilitates the adhesion of atmospheric dust, and leads to a thin hydrophilic layer on the stone surface. In the subsequent stage, it represents the diffusion medium for mono- and dibasic acids secreted by fungi, which are the direct agents of solubilization of stone minerals by the formation of salts, or acting as chelators. Among them, oxalic acid seems to play an important role in biodeterioration because high concentrations have been detected during fungal growth on laboratory media and natural substrates. Moreover, the polysaccharide sheath could facilitate carbon dioxide solubilization and formation of salts with stone minerals. Finally, the formation of melanin-polysaccharide complexes is directly involved in biodarkening. Such complexes have been described in $U$. atrum and other dark-fungi [5,46], including yeast-like species $[47,48]$, and both components have been characterized [49-52]. Fungal melanins are very resistant to biodegradation, and the complexes formed with polysaccharide and other fungal metabolites (e.g. unsaturated lipids) can contribute to black patinae on the stone surface. At this stage, the fixation of organic matter to the stone is encouraged by the ability of fungal pigments (dihydroxyperylenequinones in the case of Ulocladium) for their selective sorption on organic and mineral surfaces with weak $\mathrm{OH}$ groups. After their release from the fungal necromass, such pigments are subjected to speciation processes in the mineral matrix, seen both in natural and laboratory conditions, and accumulate in stable organo-mineral complexes $[53,54]$.
In the case of ligninolytic fungi, sheath polysaccharides also participate in the attack on wood, as illustrated in Fig. 5. Lignin degradation, the key step in wood decay, is a multienzymatic process, which in the fungi from the genus Pleurotus includes the following enzymes: laccase, $\mathrm{MnP}$ and AAO. The latter enzyme can provide $\mathrm{H}_{2} \mathrm{O}_{2}$ to $\mathrm{MnP}$, and it can also contribute to biodeterioration by generating hydroxyl radicals. $\mathrm{MnP}$ oxidizes $\mathrm{Mn}^{2+}$ to $\mathrm{Mn}^{3+}$, a compound acting as a redox intermediate during the attack on phenolic lignin moieties. The presence of LiP, an enzyme with a high redox-potential, has not been detected in these fungi, but an expanded role of laccase acting on non-phenolic lignin has been suggested in the presence of certain aromatic compounds $[55,56]$. Intermediate compounds are important in biodeterioration because the structure of sound cell-wall prevents the penetration of ligninolytic enzymes, which can diffuse only after the initial phase of attack.

In this context, the specific roles of extracellular polysaccharides in lignin biodegradation can be summarized as follows: ( $j$ ) providing a source of reducing power; $(\mathrm{k})$ facilitating the joint action of enzymes; (1) affecting the depolymerization-repolymerization balance: and $(\mathrm{m})$ facilitating the diffusion of redox intermediates. Although the participation of different enzymes in $\mathrm{H}_{2} \mathrm{O}$, generation has been suggested, the redox-cycling of aromatic substrates by the action of AAO and intracellular reductases seems to operate in Pleurotus species [57-59]. This mechanism requires a source of reducing power, which could be provided by the extracellular polysaccharide. On the other hand, the importance of enzyme immobilization by extracellular polysaccharides [41,60-63] becomes particularly evident when a system involving the synergistic action of several types of enzymes is required, as in lignin biodegradation. In fact, the joint action of the above enzymes is difficult to conceive if they are free in the extracellular medium, after being secreted by the fungus. The control of the depolymerization-repolymerization balance during lignin biodegradation could in part be done by the action of enzymes reducing lignin-derived radicals to less reactive compounds. However, a 
second possibility is the direct involvement of polysaccharide in this regulation, preventing repolymerization reactions, as suggested by Leisola and García [64]. This could correspond to the reaction between lignin-derived radicals and hydroxyl groups of polysaccharide, forming glycoside-type compounds. Finally, the polysaccharide sheath could also contribute to the action of low-molecular weight compounds acting as redox intermediates in lignin biodegradation. During the initial phase of degradation, such compounds could reach the cell-wall through diffusion in the polysaccharide sheath, which prevents lixiviation and provide a bridge from the hyphae to the cell-wall. Finally, the polysaccharide could contribute to the stabilization of some of them, e.g. acling as a chelator of $\mathrm{Mn}^{3+}$ produced by $\mathrm{MnP}$.

\section{Acknowledgements}

The authors are indebted to Dr C. Saiz-Jimenez (IRNAS, Seville) for Py-GC-MS analyses and discussion, to A. Prieto (CIB, Madrid) for her assistance in GC-MS analyses, to E. Gómez (IRNAS) for his help in scanning electron microscopy, to Dr J. Galbis (Facultad Farmacia, Seville) for NMR facilities, and to Professor F. Martín (IRNAS) for his useful suggestions. This work was partially funded by the Spanish Biotechnology Programme (BIO92-0357) and the AIR Project of the EC Biological delignification in paper manufacture (AIR2-CT93-1219).

\section{References}

[1] K. Pettersen, J. Kuroczkin, A.B. Strzelczyk and W.E. Krumbeim. Distribution and effects of fungi on and in stones. in D.R. Houghton, R.N. Smith and H.W. Eggins (Eds.). Biodeterioration 7. Elsevier Applied Science, Barking. UK. 1988, pp. 123-128.

[2] A.A. Bell and M.H. Wheeler, Biosynthesis and functions of fungal melanins. Annu. Rev. Phytopathol., 24 (1986) 411-451.

[3] J.P. Martin and K. Haider. Phenolic polymers of Stachybotns atra, Stachybotrys chartarim, and Epicoccum mgnem in relation to humic acid formation. Soil Sci.. 107 (1969) $260-270$.

[4] C. Saiz-Jimenez. K. Haider and J.P. Martin. Anthraquinones and phenols as intermediates in the formation of dark colored, humic acid-like pigments by
Eurotium echinulatum. Soil Sci. Soc. Am. Proc.. 39 (1975) 649-653.

[5] C. Saiz-Jimenez, F. Martín and A. Cert, Low boilingpoint compounds produced by pyrolysis of fungal melanins and model phenolic polymers. Soil Biol. Biochem.. II (1979) $305-310$.

[6] F. Martín, F.J. González-Vila and J.P. Martin. The persulfatc oxidation of fungal melanins. Soil Sci. Soc. Am. J., 47 (1983) 1145-1148.

[7] C. Saiz-Jimenez, The chemical nature of the melanins from Coprinus spp. Soil Sci., 136 (1983) 65-74.

[8] G. Almendros, A.T. Martinez, F.J. Martín and F. González-Vila. Degradative oxidation products of the melanin of Ulocludium utrum. Soil Biol. Biochem., 17 (1985) $723-726$

[9] G. Almendros, A.T. Martínez and E. Dorado, Production of brown and green humic-like substances by $L l o$. cladium atrum. Soil Biol. Biochem. 17 (1985) 257-259.

[10] M. Valmaseda, A.T. Martínez and G. Almendros, Contribution by pigmented fungi to P-type humic acid formation in two forest soils. Soil Biol. Biochem., 21 (1989) $23-28$

[11] European Committec for Standardization, Wood preservatives: determination of the toxic values against wood destroying basidionycetes cultured on an agar medium. European Standard, prEN 113 (1989) 1-18.

[12] A. Navarrete, La calidad en la rehabilitación de edificios desde la perspectiva de la conservación de las maderas estructurales y decorativas. Informes Construcción, 42 (1991) $61-69$.

[13] R.A. Blanchette, K.R. Cease, A.R. Abad, R.J. Koestler, E. Simpson and G.K. Sams, An evaluation of different forms of deterioration found in archaeological wood. Inr. Bindeter., 28 (1991) 3-22.

[14] K.-E.L. Eriksson. R.A. Blanchette and P. Ander, Microbial and Enzymatic Degradation of Wood Components, Springer, Berlin, 1990.

[15] D.H. Jennings and A.F. Bravery, Serpula lacrymans. Fundamentals, Biology and Control Strategies, Wiley. Chichester, 1991.

[16] F. Rune and A.P. Koch. Valid Scientific Names of Wood Decaying Fungi in Construction Timber and their Vernacular Names in England. Germany, France, Sweden, Norway and Denmark. Int. Res. Group Wood Preser., Doc. No 1546-92, 1992.

[17] T.K. Kirk and R.L. Farrell, Enzymatic combustion: the microbial degradation of lignin. Annu. Rev. Microbiol. $41(1987) 465-505$.

[18] M. Shimada and T. Higuchi. Microbial, enzymatic and biomimetic degradation of lignin, in D.N.S. Hon and N. Shiraiski (Eds), Wood and Cellulesic Chemistry, Marcel Dekker, New York, 1991, pp. 557-619.

[19] E. Odier and 1. Artaud, Degradation of lignin in $G$. Winkelmann (Ed), Microbial Degradation of Natural Products, VCH. Weinheim, 1992, pp. 161-191.

[20] H.E. Schocmaker. U. Tuor, A. Muheim. H.W.H. Schmidt and M.S.A. Leisola, White-ror degradation of lignin and 
xenobiotics, in W.B. Betts (Ed.), Biodegradation: Natural and Synthetic Materials. Springer, Berlin, 1991, pp. 157-174.

[21] I.W. Sutherland, Biotechnology of Microbial Exopolysaccharides, Cambridge University Press, Cambridge, 1990 .

[22] E. Barreto-Bergter and P.A.J. Gorin, Structural chemistry of polysaccharides from fungi and lichens. Adv. Carbohydr. Chem. Biochem. 41 (1983) 68-101

[23] P.AJ, Gorin, Carbon-13 nuclear magnetic resonance spectroscopy of polysaccharides. Adv. Carbohydr. Chem. Biochem., 38 (1981) 13-105.

[24] R.L. Whistler, A.A. Buslway, P.P. Singh, W. Nakahara and R. Tokuzen, Noncytotoxic, antitumor polysaccharides. Adv. Carbohydr. Chem. Brochem.. 32 (1976) 235-271.

[25] R.J. Seviour, S.J. Stasinopoulos, D.P.F. Auer and P.A. Gibbs, Production of pullulan and other exopolysaccharides by flamentous fungi. CRC Crit. Rev, Biotechnol, 12 (1992) $27 y-298$.

[26] S.I. Hakomori, A rapid permethylation of glycolipid and polysaccharides catalysed by methylsulfinyl carbanion in dimethyl sulfoxide, J. Biochem. (Tokyo), 55 (1964) 205-208.

[27] P.-E. Jansson, L. Kenne, H. Liedgren, B. Lindberg and J. Lonngren, A practical guide to the methylation analym ses of carbohydrates. Chem. Commun. Liniv. Stockholm, $8(1976) 1-74$

[28] G.O. Aspinall and R.J. Ferrier, A spectrophotometnc method for the determination of periodate consumed during the oxidation of carbohydrates. Chem. Ind. (London), (1957) 1216.

[29] 1. Fabre, M. Bruneteau, P. Ricci and G. Michel, Isolement el êtude structurale de glucanes de Plytophthora parasitica. Eur. J. Biochem. 142 (1984) 99-103.

[30] F.S. Archibald, A new assay for lignin-type peroxidases employing the dye Azure-B. Appl. Environ. Microbiol, 58 (1992) $3110-3116$.

[31] F. Martín, C. Saiz-Jinenez and F.J. González-Vila, The persulfate oxidation of a soil humic acid. Soil Sci., 132 (1981) $200-203$

[32] K. Matsuda and M. Schnitzer, The permanganate oxidation of humic acids extracted from acid soils. Soil Sci., $114(1972) 185 \cdots 193$.

[33] A.T. Martínez, J. Ruiz and MJ. Martinez, Influence of Mn concentration and $N$ source on the production of igninolytic enzymes in liquid cultures of Pleurotus species. Proccedings of Fifth Intcrnational Mycological Congress, Vancouver, 1994.

[34] C. Saiz-Iimenez, Microbial melanins stone monuments Sci. Total Environ., 167 (1995) 273-286.

[35] G. Almendros, A.T. Martínez, A.E. González, F. Martín and F.J. Gonzälez. Vila, Pyrolysis-gas chromatographymass spectrometry of the yeast genera Cyptococcus and Rhodotorula. Mycol. Res, 94 (1990) 211-218.

[36] C. Saiz-Jimenez, Modern concepts on the origin and structure of terrestrial humic substances: the alkylaromatic approach, in N. Senesi and T.M. Miano (Eds.), Humic Substances in the Global Environment and Implications in I Iuman Health, Elsevier, Amsterdam, 1994, pp. $71-90$.

[37] K. Kumada and M. Hurst, Green humic acids and its possible origin as a fungal metdbolite. Nuture, 214 (1967) $631-633$.

[38] D.C. Alport and J,D. Bulock, Biosynthetic pathways in Daldina concentrica. J. Chem. Soc., (1960) 654-662.

[39] L. Murmanis, T.L. Highley and J.G. Palmer, An electron microscopy study of western hemlock degradation by the white-rot fungus Ganoderma applanatum. Holzforschung. $38(1984) 11-18$.

[40] J.G. Palmer, L. Murmanis and T.L. Highley, Visualization of hyphal sheath in wood-decay Hymenomycetes. II. White-rotters. Mycologia, 75 (1983) 1005-1010.

[41] J.G. Palmer, L. Murmanis and T.L. Highley, Visualization of hyphal sheath in wood-decay Hymenomycetes. 1. Brown-rotters. Mycologia, 75 (1983) 9951004.

[42] K. Ruel and J.P. Joseleau. Involvement of an extracellular glucan sheath during degradation of Populus wood by Phanerochaete chrysosporium. Appl. Environ. Microbiol. 57 (1991) 374-384.

[43] F. Green, III, C.A. Clausen, M.J. Larsen and T.L. Highley, Immuno-scanning electron microscopic localization of extracellular wood-tegrading enzymes withm the thrillar sheath of the brown-rot fungus Postia placenta. Can. J. Microbiol. $38(1992) 898-904$

[44] I.M. Gallagher and C.S. Evans. Immunogold-cytochemical labelling of $\beta$-glucosidase in the white-rot fungus Conohis versicolor. Appl. Microbiol. Biotechnol, 32 (1990) $588-593$.

[45] G. Almendros and J. Sanz, A structural study of alkyl polymers in soil after perboratc degradation of humin. Geoderma, 53 (1992) 79-95.

[46] L.F. Linhares and J.P. Martin. Carbohydrate content of fungal humic acid-type polymers (melanins), Soil Sci. Soc. Am. J. 43 (1979) $313-318$.

[47] J.E. Zajic and A. Le Duy, Flocculant and chemica] properties of a polysaccharide from Pullularia pullulans. Appl. Microbiol., 25 (1973) 628-635.

[48] P.A. Sandford, K.A. Burton, P.R. Watson, M.C. Cadmus and $A$. Jeanes, Extracellular polysaccharide from the black yeast NRRLY-6272: improved methods for preparing a high-viscosity, pigment-free product. Appl. Microbiol, 29 (1975) 769-775.

[49] G.M. Gadd, Melanin production and differentiation in batch cultures of the polymorphic fungus Aureobasid. ium pullulans. FEMS Microbiol. Lett., 69 (1990) 237.

[50] G. Leal-Serrano, P. Rupérez and J.A. Leal, Acidic polysaccharide from Aureobatidium pullulans. Trans. Br. Mycol. Soc., 75 (1980) $57-62$.

[51] B.J. Catley, A. Ramsay and C. Servis, Observations on the structure of the fungal extracellular polysaccharide pullulan. Carbohydr. Res., 153 (1986) 74-86

[52] R.W. Silman, W.L. Bryan and T.D. Leathers, A compar- 
ison of polysaccharides from strains of Aureobasidum pululans. FEMS Microbiol Lett. 71 (1990) 65-70.

[53] G. Almendros, A. Polo and E. Dorado. Aislamiento y caracterización de dos fracciones verdes a partir de los ácidos húmicos extraídos de un podsol. Agrochimica, 26 (1982) 519-529.

[54] G. Almendros and E. Dorado, Estudio de los ácidos húmicos de tipo $\mathrm{P}$. Distribución de los pigmentos verdes en las diferentes fracciones húmicas del suelo. An. Edafol. Agrobiol., 43 (1985) 547-559.

[55] R. Bourbonnais and M.G. Paice. Oxidation of non-phenolic substrates. An expanded role for laccase in lignin biodegradation. FEBS Lett., 267 (1990) 99-102.

[56] M.J. Martíncz, C. Muñoz, F. Guillén and A.T. Martínez, Studies on homoveratric acid transformation by the ligninolytic fungus Plewous enngit. Appl. Microbiol. Biotechnol. 41 (1994) $500-504$.

[57] F. Guillén, A.T. Martínez and MJ. Martíntz, Substrate specificity and properties of the aryl-alcohol oxidase from the ligninolvic fungus Pleurous enngi. Eur. J. Biochem, 209 (1992) 603-611.

[58] F. Guillén. A.T. Martinez, M.J. Martínez and C.S. Evans, Hydrogen peroxide-producing system of Pleurotus enngii involving the extracellular enzyme aryl-alcohol oxidase. Appl. Microbiol. Biotechnol. 41 (1994) 465-470.

[59] A. Gutiérrez, L. Caramelo, A. Prieto, M.J. Martínez and
A.T. Martínez, Anisaldehyde production and aryl-alcohol oxidase and dehydrogenase activities in ligninolytic fungi from the genus Pleurotus. Appl. Environ. Microbiol., $60(1994) 1783-1788$.

[60] G. Daniel, J. Volc, E Kubatova and T. Nilsson, Ultrastructural and immunocytochemical studies on the $\mathrm{H}_{2} \mathrm{O}_{2}$-producing enzyme pyranose oxidase in Phanerochaete chnsosporikm grown under liquid culture conditions Appl. Environ. Microbiol. 58 (1992) 3667-3676.

[61] G. Danjel, J. Jellison, B. Goodell, A. Paszczynski and R. Crawford, Usc of monodonal antibodies to detcet Mn(II)-peroxidase in birch wood degraded by Phanerochate chrysosporium. Appl. Microbiol. Biotechnol., 35 (1991) 674-680.

[62] G. Danicl. B. Pettersson. T. Nilsson and J. Volc, Ust of immunogold cytochemistry to detect $\mathrm{Mn}(\mathrm{II})$-dependent and lignin peroxidases in wood degraded by the white rot fungi Phanerochacte chrsosporium and Lentinula edodes. Can. J. Bot., 65 (1990) 920-933.

[63] C.S. Evans, I.M. Gallagher, P.T. Atkey and D.A. Wood. Localisation of degradative enzymes in white-rot decay of lignocellulose. Biodegradation, 2 (1991) 93-106.

[64] M.S.A. Leisola and S. Garcia, The mechanism of lignin degradation, in M.P. Coughlan (Ed.) Enzyme Systems for Lignocellulose Degradation. Elsevier Applied Science, Barking, UK, 1989 . pp. 84-94. 